\title{
Efeito de esterco bovino sobre os rendimentos de espigas verdes e de grãos de milho
}

\author{
Jaeveson da Silva; Paulo S. Lima e Silva; Maurício de Oliveira; Kathia M. Barbosa e Silva \\ ESAM, C. Postal 137, 59625-900 Mossoró-RN; E-mail: paulosergio@esam.br
}

\section{RESUMO}

Avaliaram-se os efeitos de doses de esterco bovino $(0 ; 8 ; 16 ; 24$; 32 e $\left.40 \mathrm{t} \mathrm{ha}^{-1}\right)$ sobre os rendimentos de espigas verdes e de grãos de duas cultivares de milho (Centralmex e AG-9012). O trabalho foi realizado em Mossoró (RN), de setembro a dezembro/99, com irrigação por aspersão. Utilizou-se esquema de parcelas subdivididas no delineamento de blocos completos casualizados com três repetições. As doses de esterco foram aplicadas às parcelas e as cultivares, às subparcelas. O rendimento de milho verde foi avaliado pelo número e peso totais de espigas verdes empalhadas e pelo número e peso de espigas comercializáveis, empalhadas e despalhadas. O rendimento de grãos foi avaliado pelo peso dos grãos corrigido para $15,5 \%$ de umidade. Análises do solo, realizadas aos 120 dias após o plantio, constataram que o esterco aumentou a retenção e a disponibilidade de água e os teores de fósforo, potássio e sódio, na camada do solo de 20-40 cm, mas não influenciou o pH e os teores de cálcio, soma de bases e de matéria orgânica. Tanto o rendimento de espigas verdes como o rendimento de grãos aumentaram com o aumento da dose de esterco, exceto o número e o peso totais de espigas verdes da cultivar Centralmex. A cultivar AG-9012 foi superior à cultivar Centralmex quanto aos rendimentos de espigas verdes e de grãos. A receita líquida, calculada com a comercialização de espigas empalhadas comercializáveis, foi maior na ausência de esterco para a cultivar AG-9012 e com a aplicação de $8 \mathrm{t} \mathrm{ha}^{-1}$ para a Centralmex.

Palavras-chave: Zea mays L., adubação orgânica, milho verde, indicadores econômicos.

\begin{abstract}
The effect of cattle manure on yield of green corn ears and maize grains

The effect of different levels of cattle manure $(0 ; 8 ; 16 ; 24 ; 32$ and $40 \mathrm{t} \mathrm{ha}^{-1}$ ) on yield of green corn ears and grains of two maize cultivars was evaluated (Centralmex and AG-9012). The study was carried out at Mossoró, Rio Grande do Norte State, Brazil, from September to Dezember 1999 using sprinkler irrigation. The experimental design was complete random blocks arranged in splitplot with three replications. The manure was applied to main plots and cultivars in the subplots. The green corn yield was evaluated by total number and weight of green ears with husk and by marketables ears, with husk and without husk. The grain yield was evaluated by grain weight corrected for $15,5 \%$ humidity. The soil analysis, carried out 120 days after planting, indicated that the manure increased the water retention, water availability and the potassium, sodium and phosphorus contents, however, did not influence $\mathrm{pH}$, calcium, sum of bases and organic matter contents. The manure levels $\mathrm{x}$ cultivars interaction was significant for number of marketable ears with husk only. All evaluated traits increased with the increase of manure levels. The cultivar AG-9012 was superior to the cultivar Centralmex for the evaluated traits. The net income, obtained with the sale of marketable ears with husk, was higher when no manure was applied for AG-9012. For the cultivar Centralmex, the net income was higher with $8 \mathrm{tha}^{-1}$ cattle manure application.
\end{abstract}

Keywords: Zea mays L., organic fertilization, green corn, economic indicators.

\section{(Recebido para publicação em 30 de maio de 2003 e aceito em 20 de março de 2004)}

$\mathrm{O}$ milho é uma das principais cultu ras do Rio Grande do Norte, sendo cultivado nos 158 municípios. Essa gramínea, até há bem pouco tempo, era considerada cultura de subsistência e cultivada principalmente sob condições de sequeiro. Contudo, devido ao apoio dado à agricultura irrigada pelos governos estadual e federal, a área irrigada destinada ao milho tem aumentado e atualmente a cultura é explorada inclusive por grandes empresas que, na região, exploram a fruticultura. $\mathrm{O}$ grande interesse pelo cultivo do milho irrigado, especialmente durante a entressafra, resulta do fato de que, neste período, a demanda, tanto por espigas verdes como por grãos, é muito maior que a oferta, elevando os preços dos dois produtos.
No Rio Grande do Norte, colhe-se milho verde num período de 70 a 75 dias. Os grãos secos são colhidos 100 dias após a semeadura, aproximadamente. Assim, apenas na entressafra, de julho a dezembro, é possível a obtenção de quase três safras seguidas. Essa exploração intensiva, não apenas com milho, mas com várias outras culturas irrigadas, como o melão (Cucumis melo L.), por exemplo, provavelmente tem causado problemas físicos, químicos e biológicos para os solos que, em geral, são naturalmente pobres. Muitas áreas são abandonadas após vários cultivos. No caso do milho, é possível que os problemas sejam agravados. Como existe muito interesse pela palhada desta cultura (parte aérea da planta, sem espigas), para alimentação dos rebanhos, praticamente toda a planta é removida após cada cultivo, contribuindo para exaustão mais rápida do solo.

Os estercos foram muito utilizados no passado, mas com o advento dos adubos químicos o interesse pelos fertilizantes orgânicos diminuiu. Atualmente, a preocupação com a degradação ambiental renovou o interesse pelo uso dos estercos, ou seja, pela agricultura sustentável (Brummer, 1998; Cantliffe, 1995, Stewart e Robinson, 1997). A manutenção da matéria orgânica no solo é um dos principais fatores limitantes ao desenvolvimento da sustentabilidade nas regiões semi-áridas (Stewart e Robinson, 1997). A matéria orgânica do solo influencia o crescimento vegetal 
através de seus efeitos sobre as propriedades físicas, químicas e biológicas do solo (Stevenson, 1982). Ela possui função física, porque promove boa estrutura do solo, reduz sua compactabilidade (Zhang et al., 1997), melhorando sua aeração, o movimento e a retenção de umidade no solo (Oelsen et al., 1997; Tester, 1990). Sua função química é manifestada pela habilidade para interagir com metais, óxidos e hidróxidos metálicos e formar complexos orgânico-metálicos atuando como depósito de N, P e S (Schnitzer, 1991). Em solos ácidos sob cerrado, o efeito da matéria orgânica na disponibilidade de fósforo aplicado tem caráter temporal (Mesquita Filho e Torrent, 1993). A função biológica da matéria orgânica do solo é proporcionar $\mathrm{C}$ como fonte de energia para bactérias fixadoras de $\mathrm{N}$, aumentar o crescimento vegetal, o sistema radicular, o rendimento, a absorção de nutrientes, a síntese de clorofila e a germinação das sementes (Prakash e MacGregor, 1983)

Vários tipos de adubos orgânicos são capazes de aumentar o rendimento de grãos do milho, incluindo esterco bovino (Meneses, 1993), esterco de suínos ou cama de aves (Ernani, 1984), O esterco bovino aumenta também o rendimento da parte aérea da planta do milho cultivado para silagem (Tran e N'Dayegamiye, 1996). O objetivo do presente trabalho foi avaliar os efeitos da aplicação de doses de esterco bovino sobre os rendimentos de espigas verdes e de grãos de duas cultivares de milho.

\section{MATERIAL E MÉTODOS}

O experimento foi realizado em área da ESAM (latitude $5^{\circ} 11^{\prime} \mathrm{S}$, longitude $37^{\circ} 20^{\prime} \mathrm{W}$ e altitude de $18 \mathrm{~m}$ ), de setembro a dezembro de 1999. Os dados climáticos da região foram sumariados por Carmo Filho e Oliveira (1989). Na Tabela 1 são apresentados os dados de alguns fatores climáticos ocorridos durante o período experimental. A lâmina líquida (irrigado por aspersão) requerida para o milho $(5,6 \mathrm{~mm})$ foi calculada considerando-se ser de $0,40 \mathrm{~m}$ a profundidade efetiva do sistema radicular. $\mathrm{O}$ momento de irrigar teve por base a água retida no solo à tensão de $0,04 \mathrm{Mpa}$. O turno de rega foi de um dia. As irrigações foram iniciadas após o plantio e suspensas um dia antes de cada colheita.

A análise de uma amostra do solo experimental, um Argissolo VermelhoAmarelo (PVA), indicou: $\mathrm{pH}=7,0 ; \mathrm{Ca}=$ $2,00 \mathrm{cmol}_{\mathrm{c}} \mathrm{dm}^{-3} ; \mathrm{Mg}=0,50 \mathrm{cmol}_{\mathrm{c}} \mathrm{dm}^{-3}$; $\mathrm{K}=0,09 \mathrm{cmol}_{\mathrm{c}} \mathrm{dm}^{-3} ; \mathrm{Na}=0,01 \mathrm{cmol}_{\mathrm{c}}$ $\mathrm{dm}^{-3} ; \mathrm{Al}=0,00 \mathrm{cmol}_{\mathrm{c}} \mathrm{dm}^{-3} ; \mathrm{P}=20 \mathrm{tdm}^{-3}$; Mat. Org. $=1,90 \mathrm{~g} \mathrm{~kg}^{-1}$.

O solo foi preparado com duas gradagens. As parcelas foram marcadas e as doses de esterco $(0 ; 8 ; 16 ; 24 ; 32$ e $40 \mathrm{tha}^{-1}$ ) foram aplicadas manualmente de maneira uniforme e, a seguir, incorporadas ao solo à enxada. Uma análise do esterco, aplicado em termos de peso da matéria seca, indicou: $\mathrm{pH}=7,6 ; \mathrm{Ca}$ $=12,50 \mathrm{cmol} \mathrm{dm}^{-3} ; \mathrm{Mg}=4,70 \mathrm{cmol}_{\mathrm{c}}$ $\mathrm{dm}^{-3} ; \mathrm{K}=6,64 \mathrm{cmol}_{\mathrm{c}} \mathrm{dm}^{-3} ; \mathrm{Na}=4,32^{\mathrm{c}}$ $\mathrm{cmol}_{\mathrm{c}} \mathrm{dm}^{-3} ; \mathrm{Al}=0,00 \mathrm{cmol}_{\mathrm{c}} \mathrm{dm}^{-3} ; \mathrm{P}=$ $1245 \mathrm{t} \mathrm{dm}^{-3}$; Mat. Org. $=173,43 \mathrm{~g} \mathrm{~kg}^{-1}$. A área experimental foi sulcada e recebeu, além do esterco, $30 \mathrm{~kg}$ de N (sulfato de amônio), $60 \mathrm{~kg}$ de $\mathrm{P}_{2} \mathrm{O}_{5}$ (superfosfato simples) e $30 \mathrm{~kg}$ de $\mathrm{K}_{2}^{2} \mathrm{O}^{5}$ (cloreto de potássio), por hectare. Os adubos foram aplicados manualmente em sulcos localizados abaixo e ao lado dos sulcos de semeadura.

O plantio foi feito manualmente em 15/09/99, no espaçamento de 1,0 m x $0,4 \mathrm{~m}$, usando-se quatro sementes/cova. Aos 20 dias após o plantio, realizou-se desbaste, deixando as duas plantas mais vigorosas por cova. Portanto, o experimento, após o desbaste, ficou com uma densidade populacional equivalente a 50 mil plantas ha-1 ${ }^{-1}$ Das cultivares avaliadas, a Centralmex é de polinização-livre, tardia (ciclo de 110 dias), de porte alto (superior a $200 \mathrm{~cm}$ ), com grãos semidentados a duros de coloração amarela-avermelhada e, a AG-9012 é um híbrido triplo, de porte baixo, superprecoce, com grãos duros avermelhados.

O controle de pragas foi feito com duas pulverizações de deltamethrin $(250 \mathrm{ml}$ $\mathrm{ha}^{-1}$ ), efetuadas aos 7 e 14 dias após o plantio. O controle de invasoras foi realizado com duas capinas à enxada, efetuadas aos 20 e 45 dias após o plantio. Após cada capina, o experimento foi adubado com $30 \mathrm{~kg}$ de $\mathrm{N} \mathrm{ha}^{-1}$ (sulfato de amônio).

A colheita de espigas verdes foi realizada de dois em dois dias (à medida que os grãos atingiam o "ponto de milho verde"), durante os 70-76 dias após o plantio. Foram avaliados o número e o peso totais de espigas verdes empalhadas e o número e o peso de espigas verdes comercializáveis, empalhadas e despalhadas. Foram consideradas espigas empalhadas comercializáveis aquelas com tamanho superior a $22 \mathrm{~cm}$ e com aparência adequada à comercialização (ausência de manchas e de perfurações por pragas). Foram classificadas como espigas despalhadas comercializáveis aquelas com tamanho superior a $17 \mathrm{~cm}$ e com granação e sanidade adequadas à comercialização. A colheita das espigas maduras foi realizada aos 105 dias após a semeadura, quando os grãos apresentavam teor de umidade de, aproximadamente, 20\%. Em seguida, as espigas foram despalhadas e postas para secar ao sol por aproximadamente 72 horas quando, então, foram manualmente debulhadas. Após a pesagem dos grãos, retirou-se uma amostra de $100 \mathrm{~g}$ para estimar o teor de umidade. Com base no teor de umidade determinado, o peso dos grãos foi corrigido para um teor de umidade igual a 15,5\%. Após a colheita das espigas secas, dez plantas foram tomadas ao acaso na área útil de cada parcela para avaliação das alturas da planta (distância do nível do solo ao ponto de inserção da lâmina foliar mais alta) e de inserção da espiga (distância do nível do solo ao ponto de inserção da primeira espiga).

Aos 120 dias após a aplicação do esterco foram retiradas amostras do solo de todas as parcelas experimentais, para realização de análises física e química. As densidades do solo e de partícula, o volume total de poros, a retenção de umidade e a disponibilidade total de água, o $\mathrm{pH}$ e os teores de cálcio, magnésio, potássio, sódio, alumínio, fósforo, soma de bases e de matéria orgânica do solo foram estimados de acordo com as recomendações do Manual de Métodos de Análise de Solo (Brasil, 1997).

Utilizou-se o delineamento de blocos ao acaso com parcelas subdivididas. As doses de esterco foram aplicadas às parcelas e as cultivares, às subparcelas. Cada subparcela ficou constituída por quatro fileiras com 6,0 m de comprimen- 
Tabela 1. Médias das temperaturas máxima e mínima e umidade relativa do ar, e totais mensais de precipitação e insolação durante os meses de realização do experimento ${ }^{1}$. Mossoró, ESAM, 1999.

\begin{tabular}{lccccc}
\hline \multicolumn{1}{c}{ Mês } & $\begin{array}{c}\text { Temperatura máxima Temperatura mínima } \\
\text { do } \operatorname{ar}\left({ }^{\circ} \mathrm{C}\right)\end{array}$ & $\begin{array}{c}\text { Umidade relativa } \\
\text { do } \operatorname{ar}\left({ }^{\circ} \mathbf{C}\right)\end{array}$ & Precipitação (mm) & Insolação (h) \\
\hline Setembro & 35,4 & 23,1 & 59,4 & 0,0 & 301,8 \\
Outubro & 34,9 & 23,4 & 61,9 & 0,2 & 311,3 \\
Novembro & 34,5 & 24,1 & 66,5 & 4,0 & 286,8 \\
Dezembro & 34,3 & 24,5 & 68,4 & 15,3 & 234,5 \\
\hline
\end{tabular}

${ }_{1 / D a d o s}$ da estação meteorológica da ESAM, distante $20 \mathrm{~km}$ da área experimental.

Tabela 2. Efeitos de doses de esterco sobre características do solo, a duas profundidades, cultivado com milho. Mossoró, ESAM, 1999.

\begin{tabular}{|c|c|c|c|}
\hline Características & $\begin{array}{l}\text { Profundidade do } \\
\text { solo }(\mathrm{cm})\end{array}$ & $\begin{array}{l}\text { Efeitos da aplicação de doses de esterco } \\
\qquad\left(0 ; 8 ; 16 ; 24 ; 32 \text { e } 40 \mathrm{tha}^{-1}\right)\end{array}$ & $\mathbf{R}^{2}$ \\
\hline Retenção de água & $0-20$ & $Y=4,6905+0,1171^{* *} X$ & $0,82^{* *}$ \\
\hline$\left(\mathrm{cm} 3100 \mathrm{~cm}^{-3}\right)$ & $20-40$ & $Y=5,7619+0,1136^{* *} X$ & $0,71^{* *}$ \\
\hline Água disponível & $0-20$ & $Y=47,1633-14,3375^{* *} X 1 / 2+4,0187^{* *} X$ & $0,96^{* *}$ \\
\hline$\left(\mathrm{cm} 3100 \mathrm{~cm}^{-3}\right)$ & $20-40$ & $Y=35,3476+1,9718^{* *} X$ & $0,85^{* *}$ \\
\hline Teor de potássio & $0-20$ & $Y=0,2533$ & - \\
\hline$\left(\mathrm{cmolc} \mathrm{dm}^{-3}\right)$ & $20-40$ & $Y=0,1281+0,0049^{* *} X$ & $0,85^{* *}$ \\
\hline Teor de sódio & $0-20$ & $Y=0,2500$ & - \\
\hline$\left(\mathrm{cmolc} \mathrm{dm}^{-3}\right)$ & $20-40$ & $Y=0,1243+0,0035^{* *} X$ & $0,64^{*}$ \\
\hline Teor de fósforo & $0-20$ & $Y=7,76+0,75^{\circ} X$ & $0,92^{* *}$ \\
\hline$\left(t \mathrm{dm}^{-3}\right)$ & $20-40$ & $Y=22,34+2,65^{*} X$ & $0,91^{* *}$ \\
\hline
\end{tabular}

$\circ, * * *$ significativo a $10 \%, 5 \%$ e $1 \%$ de probabilidade, pelo teste $\mathrm{t}$, respectivamente.

to. Como área útil, considerou-se a ocupada pelas duas fileiras centrais, eliminando-se uma cova em cada extremidade. $\mathrm{Na}$ avaliação das características do solo, considerou-se também um esquema de parcelas subdivididas. Neste caso, as doses de esterco foram consideradas como parcelas e as duas profundidades de amostragem do solo $(0-20 \mathrm{~cm}$ e 20 $40 \mathrm{~cm}$ ), as subparcelas. Na área ocupada por cada cultivar foram retiradas duas amostras a cada profundidade. As duas amostras correspondentes à mesma profundidade foram misturadas e uma subamostra foi utilizada para as análises.

A análise estatística dos dados foi feita de acordo com as recomendações de Gomes (1990), usando-se o "software" desenvolvido pela Universidade Federal de Viçosa (SAEG, 1997).

Usando-se os dados relativos ao número de espigas verdes empalhadas comercializáveis, principal forma de comercialização do milho verde na região, calcularam-se a receita líquida, subtraindo-se da receita total o custo total, e a taxa de retorno, dividindo-se a receita total pelo custo total.

\section{RESULTADOS E DISCUSSÃO}

$\mathrm{Na}$ densidade do solo, houve efeito apenas de profundidade. A densidade do solo à profundidade de $0-20 \mathrm{~cm}(1,46)$ foi superior à determinada à profundidade de $20-40 \mathrm{~cm}(1,34)$. Na densidade de partículas não houve efeitos de profundidades ou da aplicação de doses de esterco (a densidade média foi de 2,62 $\mathrm{t}$ $\mathrm{m}^{-3}$ ). A porosidade total foi maior à profundidade de $20-40 \mathrm{~cm}\left(49 \mathrm{~cm}^{3} 100 \mathrm{~cm}^{-3}\right)$ do que à profundidade de $0-20 \mathrm{~cm}\left(44 \mathrm{~cm}^{3}\right.$ $100 \mathrm{~cm}^{-3}$ ), mas ela não foi influenciada pela aplicação das doses de esterco.

A retenção de umidade do solo, a $0,01 \mathrm{MPa}$, foi influenciada pela profundidade do solo e pelas doses de esterco (Tabela 2). Nas duas profundidades, o esterco aumentou linearmente a retenção de umidade, mas a retenção de umidade à profundidade de $20-40 \mathrm{~cm}$ foi sempre maior que a ocorrida na camada mais superficial. Vários pesquisadores (Hafez, 1974; Oelsen et al., 1997; Sommerfeldt e Chang, 1985; Tester, 1990; Tiarks et al., 1974) têm verificado, à semelhança do constatado no presente trabalho, que o esterco bovino aumenta a retenção de água no solo, provavelmente devido à formação de agregados (Tiarks et al., 1974). A matéria orgânica do esterco atuaria como agente cimentante na formação dos agregados (Trinca, 1999). O teor de água disponível no solo também aumentou com o aumento da dose de esterco aplicada, nas duas profundidades do solo. As equações apresentadas na Tabela 2 permitem verificar que, em geral, o teor de água disponível à profundidade de 20 $40 \mathrm{~cm}$ foi maior que aquele à profundidade de 0-20 cm. Contudo, a partir da aplicação de aproximadamente $27 \mathrm{t} \mathrm{ha}^{-1}$ de esterco, os teores de água disponível às duas profundidades não mais diferiram. A maioria das substâncias orgânica do solo aumenta sua capacidade de retenção de água devido a seu acentuado caráter hidrofílico (Trinca, 1999). 
Tabela 3. Efeitos da aplicação de doses de esterco sobre características de duas cultivares de milho. Mossoró, ESAM, $1999^{1}$

\begin{tabular}{|c|c|c|c|c|}
\hline Características & $\begin{array}{c}\text { Tukey (5\%) } \\
\text { para } \\
\text { cultivares }\end{array}$ & Cultivares & $\begin{array}{l}\text { Efeitos da aplicação de doses de esterco } \\
\qquad\left(0 ; 8 ; 16 ; 24 ; 32 \text { e } 40 \mathrm{tha}^{-1}\right)\end{array}$ & $\mathbf{R}^{2}$ \\
\hline \multirow{2}{*}{ Altura de inserção da espiga $(\mathrm{cm})$} & \multirow[t]{2}{*}{20,7} & Centralmex & $Y=123,0$ & - \\
\hline & & AG-9012 & $Y=70,0$ & - \\
\hline \multirow{2}{*}{ Altura da planta $(\mathrm{cm})$} & \multirow[t]{2}{*}{33,5} & Centralmex & $Y=205,0$ & - \\
\hline & & AG-9012 & $Y=127,41+0,61^{\circ} X$ & $0,71^{*}$ \\
\hline \multirow{2}{*}{$\begin{array}{l}N^{0} \text { total de espigas verde } e^{s} \\
\text { empalhadas ha-1 }\end{array}$} & \multirow[t]{2}{*}{$24.169,1$} & Centralmex & $Y=46117,0$ & - \\
\hline & & AG-9012 & $Y=50905,9+645,8^{* *} X 1 / 2$ & $0,77^{*}$ \\
\hline \multirow{2}{*}{$\begin{array}{l}N^{\circ} \text { espigas verdes empalhadas } \\
\text { comercializáveis ha }{ }^{-1}\end{array}$} & \multirow[t]{2}{*}{$3.925,2$} & Centralmex & $Y=31948,6+2274,2^{* *} X 1 / 2$ & $0,89^{* *}$ \\
\hline & & AG-9012 & $Y=46550,0+228,7^{* *} X-4,5^{\circ} X 2$ & $0,91^{*}$ \\
\hline \multirow{2}{*}{$\begin{array}{l}N^{\circ} \text { espigas verdes despalhadas } \\
\text { comercializáveis ha-1 }\end{array}$} & \multirow[t]{2}{*}{$8.123,5$} & Centralmex & $Y=24204,4+1266,3^{* *} X-21,0 \times 2$ & $0,87^{*}$ \\
\hline & & AG-9012 & $Y=42118,6+162,3^{*} X$ & $0,80^{*}$ \\
\hline \multirow{2}{*}{$\begin{array}{l}\text { Peso total de espigas verdes } \\
\text { empalhadas }\left(\mathrm{kg} \mathrm{ha}^{-1}\right)\end{array}$} & \multirow[t]{2}{*}{$5.494,6$} & Centralmex & $Y=11726,9$ & - \\
\hline & & AG-9012 & $Y=13645,3+99,20 * X$ & $0,81^{*}$ \\
\hline \multirow{2}{*}{$\begin{array}{l}\text { Peso de espigas empalhadas } \\
\text { comercializáveis }\left(\mathrm{kg} \mathrm{ha}^{-1}\right)\end{array}$} & \multirow[t]{2}{*}{$1.865,3$} & Centralmex & $Y=9435,5+72,3^{* *} X$ & $0,65^{\circ}$ \\
\hline & & AG-9012 & $Y=11878,1+93,7^{* *} X$ & $0,99^{* *}$ \\
\hline \multirow{2}{*}{$\begin{array}{l}\text { Peso de espigas despalhadas } \\
\text { comercializáveis }\left(\mathrm{kg} \mathrm{ha}^{-1}\right)\end{array}$} & \multirow[t]{2}{*}{$2.064,8$} & Centralmex & $Y=4359,7+69,99^{* *} X$ & $0,79^{*}$ \\
\hline & & AG-9012 & $Y=7692,9+47,0^{*} X$ & $0,97^{* *}$ \\
\hline \multirow{2}{*}{ Rendimento de grãos $\left(\mathrm{kg} \mathrm{ha}^{-1}\right)$} & \multirow[t]{2}{*}{$1.291,6$} & Centralmex & $Y=3944,9+52,1^{* *} X$ & $0,71^{*}$ \\
\hline & & AG-9012 & $Y=5535,4+46,2^{* *} X$ & $0,90^{* *}$ \\
\hline
\end{tabular}

$\circ, *, * *$ significativo a $10 \%, 5 \%$ e $1 \%$ de probabilidade, pelo teste $t$, respectivamente.

$\mathrm{O}$ valor do $\mathrm{pH}$, os teores trocáveis de cálcio e magnésio e o teor de matéria orgânica foram maiores à profundidade de $0-20 \mathrm{~cm}\left(8,1 ; 3,2 \mathrm{cmol}_{\mathrm{c}} \mathrm{dm}^{-3} ; 1,2\right.$ $\mathrm{cmol}_{\mathrm{c}} \mathrm{dm}^{-3} \mathrm{e} 8,14 \mathrm{~g} \mathrm{~kg}^{-1}$, respectivamente) que os valores respectivos à profundidade de $20-40 \mathrm{~cm}\left(7,8 ; 2,0 \mathrm{cmol}_{\mathrm{c}}\right.$ $\mathrm{dm}^{-3 ;} 0,7 \mathrm{cmol}_{\mathrm{c}} \mathrm{dm}^{-3} \mathrm{e} 4,2 \mathrm{~g} \mathrm{~kg}^{-1}$, respectivamente). Nestas características a aplicação de doses de esterco não teve efeito. A aplicação de doses de esterco não influenciou o teor de potássio à profundidade de $0-20 \mathrm{~cm}$, mas aumentou linearmente este teor à profundidade de 20$40 \mathrm{~cm}$ (Tabela 2). Contudo, não houve diferença entre as duas profundidades, quanto ao teor de potássio, no intervalo de doses de esterco avaliadas. Efeitos semelhantes de doses de esterco aplicadas e de profundidades foram observados no teor de sódio (Tabela 2). A aplicação de doses de esterco aumentou linearmente o teor de fósforo nas duas profundidades do solo, mas os aumentos foram maiores à profundidade de 20$40 \mathrm{~cm}$, de modo que a partir da aplicação de, aproximadamente, $12 \mathrm{t} \mathrm{ha}^{-1}$, o teor de fósforo à profundidade de 20-40 $\mathrm{cm}$ foi maior que o determinado na camada mais superficial. Meneses (1993), à semelhança do encontrado no presen- te trabalho, também verificou aumentos lineares nos teores de potássio e fósforo, com o aumento da dose de esterco, mas ele verificou ainda aumentos do $\mathrm{pH}$ e dos teores de $\mathrm{Mg}$ e matéria orgânica, o que não foi constatado no presente estudo. Deve ser mencionado, contudo, que Menezes (1993) testou doses de esterco superiores (até $60 \mathrm{t}^{\text {ha-1 }}{ }^{-1}$ ) às avaliadas neste trabalho. Ernani e Gianello (1982), por outro lado, de modo semelhante ao observado no presente estudo, constataram que resíduos orgânicos aplicados ao solo não afetaram o nível de matéria orgânica no solo.

A aplicação de doses de esterco não influenciou a altura de inserção da espiga das cultivares avaliadas, mas a cultivar Centralmex foi superior à cultivar AG-9012 quanto a este caráter (Tabela $3)$. As doses de esterco aplicadas também não influenciaram a altura da planta da cultivar Centralmex, mas aumentaram linearmente a altura da planta da outra cultivar (Tabela 3). Apesar dos acréscimos observados na altura da planta da cultivar AG 9012, ela foi sempre inferior à cultivar Centralmex, no intervalo de doses de esterco avaliadas.

A aplicação do esterco aumentou o número total de espigas verdes empalhadas da cultivar AG-9012, mas não influenciou esta característica na cultivar Centralmex (média de 46.117 espigas ha $\left.^{-1}\right)($ Tabela 3$)$. Apesar dos acréscimos observados na cultivar AG-9012, as cultivares não diferiram entre si.

$\mathrm{O}$ esterco aumentou o número de espigas empalhadas comercializáveis das duas cultivares (Tabela 3). Apesar da cultivar AG-9012 ter apresentado maiores níveis de produtividade que a outra cultivar, o fato dos acréscimos em rendimento terem sido maiores na cultivar Centralmex, fez com que a partir da dose de $34 \mathrm{t} \mathrm{ha}^{-1}$, as cultivares não mais tenham diferido entre si. Portanto, apesar do esterco não ter influenciado o número total de espigas verdes da cultivar Centralmex, aumentou nela a proporção de espigas verdes comercializáveis.

Também no caso do número de espigas despalhadas comercializáveis a cultivar AG-9012 apresentou maiores níveis de produtividade que a cultivar Centralmex, apesar desta cultivar ter apresentado acréscimos maiores que aquela, com o aumento da dose de esterco. Vale ressaltar que enquanto o número de espigas despalhadas comercializáveis da cultivar AG-9012 
Tabela 4. Indicadores econômicos do rendimento de espigas verdes empalhadas comercializáveis de duas cultivares de milho ${ }^{1}$ Mossoró, ESAM, 1999.

\begin{tabular}{|c|c|c|c|c|c|}
\hline \multirow{2}{*}{ Cultivar } & Doses de esterco & Custos totais $\mathrm{ha}^{-1}$ & Receitas totais ha-1 & Receita líquida ha ${ }^{-1}$ & Taxa de retorno \\
\hline & $\left(t\right.$ ha $\left.^{-1}\right)$ & \multicolumn{4}{|c|}{$R \$ 1,00$} \\
\hline \multirow{6}{*}{ Centralmex } & 0 & 835 & 1891 & 1056 & 2,26 \\
\hline & 8 & 1074 & 2414 & 1340 & 2,25 \\
\hline & 16 & 1313 & 2338 & 1025 & 1,78 \\
\hline & 24 & 1551 & 2558 & 1007 & 1,65 \\
\hline & 32 & 1790 & 2845 & 1055 & 1,59 \\
\hline & 40 & 2029 & 2691 & 662 & 1,33 \\
\hline \multirow{6}{*}{ AG-9012 } & 0 & 835 & 2801 & 1966 & 3,35 \\
\hline & 8 & 1074 & 2870 & 1796 & 2,67 \\
\hline & 16 & 1313 & 2936 & 1623 & 2,24 \\
\hline & 24 & 1551 & 3000 & 1449 & 1,93 \\
\hline & 32 & 1790 & 2932 & 1142 & 1,64 \\
\hline & 40 & 2029 & 2915 & 886 & 1,44 \\
\hline
\end{tabular}

${ }^{1 /}$ Milheiro de espigas $=\mathrm{R} \$ 60,00($ EMPARN, Mossoró-RN).

aumentou linearmente, na cultivar Centralmex ele alcançou um máximo com a aplicação de $30 \mathrm{t} \mathrm{ha}^{-1}$ de esterco, aproximadamente. As duas cultivares diferiram entre si até a dose aproximada de $11 \mathrm{t} \mathrm{ha}^{-1}$ de esterco, mas a partir desta dose não houve mais diferença entre elas.

A aplicação de esterco não influenciou o peso total de espigas verdes empalhadas da cultivar Centralmex, mas aumentou linearmente esta característica na cultivar AG-9012 (Tabela 3). O peso de espigas verdes empalhadas comercializáveis aumentou linearmente nas duas cultivares, com a aplicação das doses de esterco (Tabela 3). Em todas as doses avaliadas houve superioridade da cultivar AG-9012, quanto à mencionada característica. Efeito semelhante foi observado no peso de espigas despalhadas comercializáveis. Isto é, a aplicação do esterco aumentou linearmente o peso de espigas despalhadas comercializáveis das duas cultivares avaliadas, que diferiram entre si no intervalo estudado de aplicação do adubo.

$\mathrm{O}$ esterco aumentou linearmente o rendimento de grãos das duas cultivares, que diferiram entre si no intervalo das doses aplicadas (Tabela 3).

Da Tabela 3 infere-se que a aplicação de esterco bovino é um meio efetivo para aumentar o rendimento de espigas verdes comercializáveis de milho, pois, nas duas cultivares, houve aumento no número e peso de espigas empalhadas ou despalhadas, com o aumento da dose de esterco aplicada. O esterco foi também eficiente para elevar o rendimento de grãos (Tabela 3). Não foram encontrados, na literatura consultada, trabalhos tratando dos efeitos de doses de esterco sobre o rendimento de milho verde. Portanto, uma discussão comparativa com os resultados de outros autores fica limitada. Contudo, os resultados obtidos com grãos secos apóiam os obtidos no presente trabalho. Meneses (1993) verificou que a aplicação de doses que variaram de 0 a 60 t ha $^{-1}$ aumentou o rendimento de grãos do milho de forma linear, no monocultivo, e de forma quadrática quando o milho foi consorciado com o caupi (Vigna unguiculata (L.) Walp.).

Os acréscimos em rendimento obtidos com a aplicação do esterco certamente foram devidos aos benefícios deste fertilizante as propriedades físicas, químicas e biológicas do solo, alguns dos quais constatados no presente trabalho (Tabela 2). Um dos efeitos positivos da aplicação de matéria orgânica é o suprimento de nutrientes de forma equilibrada (Alves et al., 2000). Isto é, o equilíbrio entre elementos nutritivos seria mais importante no ganho de produtividade das plantas do que maiores quantidades de macronutrientes isoladamente (Primavesi, 1985). Trinca (1999) argumenta que a disponibilização de nutrientes com a adubação orgânica pode ser considerada sob dois aspectos. O primeiro é que a mesma constitui uma fonte direta de macro e micronutrientes, via processo de mineralização. O segundo se refere à participação da fração orgânica em processos que melhoram a disponibilidade de tais nutrientes. Devido ao seu elevado teor de carbono a matéria orgânica é a fonte energética por excelência para a ocorrência de diversos processos biológicos, que melhoram a disponibilidade de nutrientes do solo. Dentre esses processos merecem destaque a fixação biológica do nitrogênio, em associações simbióticas e assimbióticas, e a disponibilização de fósforo em associações micorrízicas. Além disso, a matéria orgânica pode formar com metais compostos com elevada estabilidade conhecidos como quelatos. Esses metais se tornam mais disponíveis para as plantas porque os compostos apresentam maior solubilidade e porque muitos dos exudatos radiculares são capazes de retirar estes elementos das estruturas formadas com a matéria orgânica.

A análise econômica baseada em dados de números de espigas empalhadas comercializáveis indicou que a maior receita líquida foi obtida com a aplicação de $8 \mathrm{t} \mathrm{ha}^{-1}$ (Tabela 4 ) na cultivar Centralmex. Na cultivar AG9012, a maior receita líquida foi obtida sem a aplicação de esterco. Alves et al. (2000) constataram que a aplicação de determinadas fontes de matéria orgânica não é economicamente viável na produção de sementes de feijão-vagem. 
As diferenças de resposta entre cultivares, no que se refere aos rendimentos de espigas verdes, de grãos e de receitas líquidas talvez estejam relacionadas ao fato de que a cultivar AG-9012 é uma cultivar moderna, que sofreu mais melhoramento e que, possivelmente, deve aproveitar mais eficientemente os recursos ambientais disponíveis. Isto talvez explique, inclusive, a obtenção de maior receita líquida, mesmo sem a aplicação de esterco. Castleberry et al. (1984) verificaram que as cultivares melhoradas produziram mais que as não-melhoradas nos ambientes favoráveis (solo adubado ou área irrigada) e desfavoráveis (solo não-adubado ou área não-irrigada), mas as diferenças entre as cultivares melhoradas e não-melhoradas foram maiores nos ambientes favoráveis.

Pode-se concluir, portanto, que o esterco aumentou a retenção e a disponibilidade de água e os teores de fósforo, potássio e sódio, na camada do solo de $20-40 \mathrm{~cm}$, mas não influenciou o pH e os teores de cálcio, soma de bases e de matéria orgânica. O rendimento de espigas verdes e o rendimento de grãos aumentaram com o aumento da dose de esterco, exceto o número e o peso totais de espigas verdes da cultivar Centralmex. A altura da planta foi aumentada pelo esterco apenas na cultivar AG-9012. A cultivar AG-9012 foi superior à cultivar Centralmex quanto aos rendimentos de espigas verdes e de grãos, mas o inverso foi verdadeiro nas alturas da planta e de inserção da espiga. A receita líquida, calculada com a comercialização de espigas empalhadas comercializáveis, foi maior na ausência de esterco para a cultivar AG-9012 e com a aplicação de $8 \mathrm{t}$ ha $^{-1}$ para a Centralmex.

\section{LITERATURA CITADA}

ALVES, E.U.; OLIVEIRA, A.P.; BRUNO, R.L.A.; ARAÚJO, E.; SILVA, J.A.L.; GONÇALVES, E.P.; COSTA, C.C. Produção de sementes de feijão-vagem em função de fontes e doses de matéria orgânica. Horticultura Brasileira, Brasília, v.18, n.3, p.215-221, 2000.

BIEDERBECK, V.O.; CAMPBELL, C.A.; HUNTER, J.H. Tillage effects on soil microbial and biochemical characteristics in a fallow-wheat rotation in a Dark Brown soil. Canadian Journal of Soil Science, v.77, n.2, p.309-316, 1997.

BRASIL, Ministério da Agricultura. Manual de métodos de análise de solo. 2 ed. Rio de Janeiro, EMBRAPA/CNPS, 1997. 212 p.

BRUMMER, E.C. Diversity, stability and sustainable american agriculture. Agronomy Journal, v.90, n.1, p.1-2, 1998.

CANTLIFFE, D.J. Challenges facing horticulture in a changing world Presidential Address. HortScience, Alexandria, v.30, n.7, p.1139-1340, 1995.

CARMO FILHO, F.; OLIVEIRA, O.F. Mossoró: um município do semi-árido nordestino. Mossoró Fundação Guimarães Duque/ESAM, 1989. 69 p. (Coleção Mossoroense, série B, $\mathrm{n}^{\circ}$ 672).

CASTLEBERRY, R.M.; CRUM, C.W.; KRULL, C.F. Genetic yield improvement of U.S. maize cultivars under varying fertility and climatic environments. Crop Science, v.24, p.33-36, 1984. ERNANI, P.R. Necessidade de adição de nitrogênio para o milho em solo fertilizado com esterco de suínos, cama de aves e adubos minerais. $R e$ vista Brasileira de Ciência do Solo, Campinas, v.8, n.3, p.313-317, 1984.

ERNANI, P.R.; GIANELLO, C. Efeito imediato e residual de materiais orgânicos, adubo mineral e calcário no rendimento vegetal. Revista Brasileira de Ciência do Solo, Campinas, v.6, p.119124, 1982.

GOMES, F.P. Estatistica experimental. 13 ed. Piracicaba: Nobel, 1990. 467 p.

HAFEZ, A.A.R. Comparative changes in soilphysical properties induced by mixtures of manures from various domestic animals. Soil Science, Baltimore, v.118, p.53-59, 1974.

MENESES, O.B. Efeitos de doses de esterco no rendimento do feijão-de-corda e do milho em cultivos isolados e consorciados. Mossoró: ESAM, 1993. (Tese mestrado).
MESQUITA FILHO, M.V.; TORRENT, J. Phosphate sorption as related to mineralogy of a hydrosequence of soils from the Cerrado region (Brazil). Geoderma, v.58, n.1, p.107-123, 1993.

OELSEN, T.; MOLDRUP, P.; HENRIKSEN, K. Modeling diffusion and reaction in soils: VI. Ion diffusion and water characteristics in organic manure-amended soil. Soil Science, v.162, n.6, p.399-409, 1997.

PRAKASH, A.; MACGREGOR, D.J. Environmental and human health significance of humic materials: an overview. In: CHRISTIMAN, R.F.; GJESSING, E.T. (Eds.) Aquatic and terrestrial humic materials. Woburn, Ann Arbor Science, 1983. p.481-494.

PRIMAVESI, A. Manejo ecológico do solo: a agricultura em regiões tropicais. 8.ed. São Paulo, Nobel, 1985. $541 \mathrm{p}$.

SAEG. Sistemas para análises estatísticas, 7.0. Viçosa: Fundação Arthur Bernardes, UFV/DBG, 1997. SCHNITZER, M. Soil organic matter- the next 75 years. Soil Science, v.151, n.1, p. 41-58, 1991. SOMMERFELDT, T.G.; CHANG, C. Soil-water properties as affected by twelve annual applications of cattle feedlot manure. Soil Science Society of American Journal, v.49, p.983-987, 1985.

STEVENSON, F.J. Humus chemistry. Somerset, John Wiley and Sons, 1982.

STEWART, B.A.; ROBINSON, C.R. Are agroecosystems sustainable in semiarid regions? Advances in Agronomy, v.60, p.191-228, 1997.

TESTER, C.F. Organic amendment effects on physical and chemical properties of a sandy soil. Soil Science Society of American Journal, v.54, p.827-831, 1990.

TIARKS, A.E.; MAZURAK, A.P.; CHESNIN, L. Physical and chemical properties of soil associated with heavy applications of manure from cattle feedlots. Soil Science Society of American Journal, v.38, p.826-830, 1974.

TRAN, T.S.; N'DAYEGAMIYE, A. Longterm effects of fertilizers and manure application on the forms and availability of soil phosphorus. Canadian Journal of Soil Science, v.75, n.3, p.281285, 1995.

TRINCA, C.R. de. Materia organica del suelo. Revista Alcance, v.57, p.53-72, 1999.

ZHANG, H.; HARTGE, K.H.; RINGE, H. Effectiveness of organic matter incorporation in reducing soil compactibility. Soil Science Society of American Journal, v.61, p.239-245, 1997. 